\title{
An Assessment of Youth Participation in Community Development programmes in Damaturu Local Government Area Yobe State, Nigeria.
}

\author{
${ }^{1}$ Umar Lawal Yusuf, ${ }^{2}$ Mohammed Ali Mechanic \\ ${ }^{I}$ Department of Sociology Yobe State University Damaturu, Nigeria. \\ ${ }^{2}$ Department of Sociology and Anthropology University of Maiduguri, Nigeria.
}

\begin{abstract}
This paper assesses youth participation in community development in Damaturu local government Area, Yobe State, Nigeria. The study utilizes the simple random sampling techniques to generate the data. In term of data collection, two main methods were used. They are primary and secondary sources of data collection. The questionnaire was used as an instrument for data collection. In data analysis, simple percentage and tabulation were employed to analyzed data sought from the field. The finding revealed that most of the youth contribute to community development through communal labor, through provision of security and maintenance of footpaths, and re-orientation of moral support by the elites is one of the ways to address the problem faced by the youth in the community. The study concluded that, youth involvement in community development is one of the cardinal principles of designing programmes and should be central to the development effort of the community.
\end{abstract}

Key words: youth, participation, community development

\section{Introduction}

Nigeria is endowed with enormous human and natural resources. However, strategies and policies by various governments have not effectively harnessed these resource to the benefit of the country and the citizens. Community development have an implicit potentials to improve the collective well being of citizens and make positive inclination for everyone to embrace the democratic ideals of fairness, justice, transparencies and hard work (Ginwright \& James, 2002). Furthermore, Adedoyin (1997), posit that the nature and scope of community development are very important factors upon which dimension of development in community are based or structures. This is well understood amidst a thorough study of communities and the basic environment for community development.

Jibowo (1992), see development as the transformation of the rural community in to socially, economically, politically, educationally, orderly, materially of desired conditions with the purpose of improving quality of life of the rural communities or population. However, Ekong (2003), Assert that, community development in developing countries generally entails the emphasis on participation of youth by the local community. He further stated that involvement of people in programme entail understanding the nature of the problems involved, those directly involved and those peripherally affected.

The development of community is a process that embraced all spheres of the society including the youths. The key component of this process is found in the creation and maintenance of channels of interaction and communication among diverse local group that are otherwise directed toward individual interest. During the colonial era and after word, community infrastructure where constructed out of the community effort with active participation of youths. In view of these, youth are seen as a cornerstone of their communities and their participation in this community is known to be pre-requisite for the overall development of their communities (U N, 2002).

The youth in Nigeria can be put into public or private ventures (PPV) which reflect a similar effort at making them to be part of the entire society, it has joined with community organization in several cities whether rural or urban communities the increase neighborhood support for youth development in the community change for youth development (CCYD) initiative. Public or private ventures described community change for youth development as a theory - based community change for development initiatives, that is enable the youth of the communities to create and embody a theory. In this case, a theory of what youth must have for healthy development in playing their role in community. Community change for youth development (CCYD) theory is reflected in its three to five core concept. (Lane, 1996).

If we take mental trips across Nigeria today from north to the south and from east to the west, the common stories or history are those of armed conflict, armed robbery, hunger and outright starvation, poverty, disease totalitarian governance, extra - judicial killing, corruption, misappropriation of public funds, electoral 
fraud to gain power arrogance, and flamboyancy. The economy has been badly damaged with debt so compounding that it will take time to determine the youth of the next four (4) generation to settle. With all these, it is obvious that the old brigade have never seen anything good in young people apart from the time they needs them as political thugs and also these in turn create a lack of direction for youth and some youth have been mislead by manipulation of ethnicity and religion (Connell 1992).

Today, national youth development organization and intermediate as well as local community based youth development organization (LBO) are engaged in effort to expand their vision and practice to link youth development and community development. Notably, the national network for youth have together articulated a concept of community youth development as the under pining of their work. Community youth development now serve as both a reconsideration of the work of this organization and a framework guiding staff and organizational development and programmes design. The national network for youth described it as a holistic system and a strength based approach to work with young people. Community youth development value and respect of young people, address the whole people rather than one aspect, and involves family, communities and other system of support to create healthy youth, strong family are responsible communities process (Lane, 1996). Although, youth organization and identify support are potentially powerful strategies for youth development, the research is insufficient for demonstrating how effective they are to achieve desired community engagement outcome and supporting the holistic development of youth (Lane, 1992).

However, Ekong (2003), argued that the youth have been active participant in the happning of their own destiny as well as building the development of the nation. He also posits that the youth are predominant in agriculture which is now accounted for $40 \%$ of national G.D.P (Gross Domestic Product) despite the heavy dependence of the economy on oil. In his view about $60 \%$ of the youth live in rural areas and derived their livelihood from agriculture and related activities. In view of all these the youth are the life wire of Nigeria and society combining their limited stock of capital and rudimentary equipment with their labour, they are dominant economic activities in the rural sector and have been the principal vehicle for economic expansion. Generally, the participation of youth in community development is particularly in Damaturu local government area in Yobe state, it is important to keep them together to love one another in the community. Since the communities throughout the state are faced with extensive growth pressure, significant socio-demographic changes and a growing youth population it at an alarming rate due mainly to the new nature of the State. Such condition suggests an important role for the youth to play in local planning and decision making (Unite Nation, 2002).

The involvement of youth and their active collaboration with adult contribute to the local community development, while presenting opportunities for personal self growth, skill enhancement and leadership development. It is also evident that successful youth or adult partnership encourages youth to develop the capacity to serve in organization and can actively become a community leader. Therefore, the United Nation (2002), posit that, youth participation are known to be prerequisite for overall development of community. This study is centered on the facts that youth are pivotal in the development of society which can be positive or negative.

\section{Statement of the Problems}

Youth are the most vital resources for community development, the ability and capacity of the youth to derived benefit from and contribute to community development depend on whether they are correctly guided adequately mobilized and inadequately centered for the development programmes. Thus a direct need exist for programmes and policy planners to better understand the role, impact and possibilities presented by youth's involvement in the community development process. Historically, youths are input in decision making, solving problems, local action and evaluation in communities has received only limited attention. However, the recent trend suggests that youth are playing an increasingly important role in development of their communities.

Despite the potential of youth, they are still confronted with many challenges that hinder them from participating activities in community development. The post school period is characterized by unemployment which is capable of sending disturbing signals to all segment of society. Other hindrance to active involvement of youth in community development is bad leadership corruption political instability, insecurity, poverty and poor economic management of the nation. This in turn creates lack of direction for youth and thus some have been mislead by manipulation of ethnicity and religion. More so, youths are sitting at home in front of their television playing video games, watching football instead of battering themselves by going to work. They have no vision and no dream and so do not have drive to make any attempt at achieving a set of goal. Thus, against this backdrop this paper is intended to assess the following questions:

1. What are the levels of youth participation in community development programmes in Damaturu local government Area? 
2. What are the hindrances of youth participation to community development in Damaturu local government Area?

3. What are types of programmes youth engage toward community development in Damaturu local government Area?

4. Which of the changes and contribution does the youth brought in community development in Damaturu local government?

\section{Objectives of the Study}

The general aim of this study is to assess the youth participation in community development and other factors associated with youth in community development in Damaturu local government Area. The specific objectives are as follows:

1. Examine the level of youth participation to community development programmes in Damaturu local government Area.

2. Identify some hindrances of youth participation to community development in Damaturu local government Area.

3. Find out the types of programmes youth engage toward community development in Damaturu local government Area.

4. To identify changes and contributions youth brought through community development in Damaturu local government Area.

\section{Significance of the Study}

The significance of the study will bring to lime light the participation of youth in community development. The research will further suggest probable way or means of transforming and managing the youth who are leaders of tomorrow. The finding of this research will also help policy makers on how to actively engage in the community development by expanding the academic endeavors and to add more knowledge as well as to help the policy makers and planner.

\section{Literature Review}

In the course of seeking explanation to a particular phenomenon, scholars in different fields of endeavors have continued to elicit information which presents a better understanding of the phenomenon. This chapter attempt to review some of the work done by scholars that are related to the youth participation in community development in Nigeria in general and in Damaturu local government, Yobe state particular. Attention will be focused on the concept of development, the concept of community, the concept of community development, the concept of youth in community development and also the theoretical explanation of the phenomenon.

\section{The Concept of Development}

The term development means different things to different people. Some people take the mean a change; others take it as an advancement, improvement and progress. In its ethnocentric sense, some scholars regard it as modernization and westernization. As a social science construct, development means different things to different people. Writing at the turn to the twentieth century, Lane (1992) a leader of the great October 1917 Russian revolution defined development as a progressive movement, as ascension from lower to higher stage and from simple to complex situation.

The simple/lower stages refer to the stage of nature in which the society itself is a process of social evolution. Division of labour at this level is rudimentary. Nearly every member of the society performs similar roles and function. The transition to the complex stage result from certain need which arise from the society's division of labour, and was raised to a higher status with every member of society assigned to a specific role and function in the stratification system.

Development is also the ability of man to conquer his environment and utilize it to his advantage. The process involve in development tools, are skills and mobilization of required resources for development process. Development also implies increase in output per head but which transcends individual levels. Rodney (2005) argued that, development is a broad and multi - dimensional concept; it is better appreciated at social level. In the course of defining development there are those who have taken development for growth. Sherrod (2000) for example defined development as a check list of technical artifacts to him, the availability of school, hospital, road network, electricity, boreholes, and other infrastructural facilities are indication of development even though the school, hospital, road network, electricity do not provide qualitative service to the target population. It should be pointed out that the availability of these facilities or artifacts alone does not qualify a society as developed one, such progress is taken to be growth instead of development. 
Sherrod (2000), raises so many questions as a key for understanding development. For example, he maintains that the questions to ask about the country's development are three: what has been happening to poverty? What has been happening to unemployment? What has been happening to inequality? If these entire three questions have declined from higher level then there is no doubt this has been a period of development for the country concerned. All of the above are clear indication that development does not have a precise definition nevertheless; development means qualitative and quantitative changes in structure, composition and performances of a force of production. It is indicates in the quantitative living standard of the peoples via eradication of poverty. Unemployment, hunger, diseases, squalor, inequality are the major social problems that requires elimination or drastic reduction. It is not clear to conclude that development has taken place. Because in every level of development we look at our indicators of positives changes in the quality of development and useful life span of people as follows:

1. Ability to feed, clothe and shelter resulting from more income earned from one occupation and the provision of infrastructural facilities like road, water, electricity, telecommunication, and improve other factors of production.

2. Ability to live much longer as a result of provision of wealth and medical facilities prevention of disease through better sanitation and other preventive measure.

3. Ability to read, write and to understand force surrounding one through provision of formal and informal education.

4. Ability to participate meaningfully in political activities and in policy making at governmental level as well as the community level.

Therefore, man is the centre of development, the ultimate goal in his well being is happiness and comfort.

\section{The Concept of Community}

The term "community" as used in this research means a territorially bounded social systems within which people live in harmony, level affection, intimacy and share common social, economic and cultural as well as political characteristics community usually refer to setting contexts and social relation. In many community and neighborhood are used interchangeably to refer to geographical area and its people and resources within it. In community planning, however, community often refer to the relationship among places, social relationship, economic and political forces,(Cahill, 1997).

To chamber (1978), defined community as a population living within a legal established city limit where the people have some social and economics features in common which enables them to pursue a common goals. Community may contain more than one ethnic group having slightly different ways of life. The common bond that ties them together is the socio economics problems which they fight together to resolve. The community made up of individual and must forfeit four purposes; viz survival self fulfillment, the nation of affection love throughout life and enhance of human culture $\left(4^{\text {th }}\right.$ National Development Plan Vol1).

Therefore, the term "culture" is used here to mean the sum total of accumulated knowledge; tradition and wisdom which each of us inherit from those who have live before us (Gambone, 2002). Community must survive, that is, it must remain as indivisible and identifiable entity. This can be achieved through staying together and pursue a common goals and to fight any destructive element either from inside or outside that may cause a split within itself.

Ultimately aspect of community life that affect young people's development include safety, opportunity for positive relationship and a sense of belonging, economic opportunity, adequate physical development and infrastructure(such as housing, transportation, open space and amenities), labour market condition and schools. Dryfoos (1990) summarized this research finding on community for youth in this way: whether and how young people meet their basic needs and apply competencies they develop depends in large part on the strength and direction of influences in their lives. Research and theory suggest that family, peers, school, community group, religion organization, place of employment, plus larger social force such as neighborhood resources and the job are all important of youth development (Ginwright \& James, 2002).

\section{An Overview of Community Development}

United Nation (2002), posits that the term community development has come in to international usage to connote the process by which the effort of the people themselves are united with those of government authority to improve the economics, social and cultural condition of communities to Integrated these community into the like of the nation and enable them to contribute fully to national progress or development. Two important element of this definition are people's effort and governmental and nongovernmental assistance. People efforts here include their participation in initiating planning and execution of project with as much reliance as possible on their own initiative and resources. Governmental and nongovernmental assistance here 
means the provision of technical, financial and other services in such a way that will encourage in self-help/ self-reliance.

On the other hand Adedoyin (1997) argued that community development is a method of helping local community to become aware of their needs, to assess their resource more realistically, to organize themselves and their resources and such a way as to satisfy some of their needs and so doing, acquire the attitude, experience and co-operative skills for repeating the process again on their own initiative. By this definition, community development is a process in the sense that it is a dynamic sequence which when set in motion, supplies its own motive power, so that people in the community through their own effort one enabled to move steady towards the goals of self improvement.

To Chambers (1978), community development is an educational process. It is not better road, better bridge, pure water nor better sanitation. It is something of the spirit more than something of material. It must reach into deep, cultural pattern of the people, examining them and testing them as principles of faith. It is not temporary, physical construction. It is a building within the heart and mind of men, not a recreation centre in the middle of a field the point made in this statement is that community development is much more that construction of physical things. It must be a ways of life of a community embraced by every member of that community. With that, all physical solution to problems shall follows and in their proper order.

Today, national youth development organization and intermediaries, as well as local community based youth development organization (CBOS), are engage in effort to expand their vision and practice to link youth development and community. Notably, the national network for youth, in and the national UH have together articulated a concept of "community development" as the underpinning of their work. Community youth development serves as both a reconsideration of the work of these organizations and a frame work guiding staff and organizational development and program design. The national network for youth describe as a holistic system and strength base approach to working with young people. (community youth development) value and respect young people, address the whole person rather than one aspect and involve families, communities and other systems to support to creates healthy youth, strong families and responsible communities. (Lane, 1992).

\section{The Role of Youth in community Development in Nigeria}

Cahill (1997) define youth development as the process of young and adult working in partnership to create the necessary condition that will result in the successful development of young people their peers, family and community the integration of youth development and community development.

The study of active youth participation in community development is in many ways an important field of inquiry. Both the community and youth can benefit greatly from the involvement of young resident in all aspect of the community development process. Therefore, youth involvement in true for most youth serving agencies, all of the organization in this nation is less successful in providing youth with optimal opportunities for meaningful youth involvement than with other developmental experiences. However, greater opportunities of youth in the youth organizing agencies report consistently receiving opportunities for meaningful involvement scale and two effects Connell (2002).

It is important to note that, young people can became empowered to be part of the problem solving, decision makers and committed leader who will lead community development effort in future. Through the active interaction of youth and adults, a more representatives voices are provided that reflect the diverse need and want of the community. Young are the crucial segment of society; they are the verses for future development. Young are social actors of change and can serve as a pressure group to challenge/ lobbying government in defining their properties. It has been clearly stress that a youth are not the only leaders of tomorrow, but the partner of today.

The former united nation secretary general, Kofi Annan underline the role of youth as actors who have real expertise complementary to that of academic and researchers. It is important to strive toward the involvement of young people as active citizen. While much of the attention given to building capacity (local capacities is often focused toward adult and civic organization), youth are an increasingly visible and active component in community development effort. The community is the first entity that all of us encounter beyond our families. It is important to note that, youth have to clearly define role and opportunities which allows them to actively participation in their community rather than having passive role. Relationship between the youth and community building are a key to long term involvement in community development effort (Sherrod, 2000).

Furthermore, civic engagement, such as civic education and opportunities for involvement in school extra curriculum activities is an important element of community involvement for youths. Youths represented the larger society where they may practice skills, Other aspect such as teacher behavior, school climate or condition, instructional style that promote dialogue, discussion and school policies may help or assist in defining good citizenship (Ginwright \& James 2002). Therefore, promoting youth involvement and serving as indirect motivators or opportunities for leadership are also necessary in order to develop young people and prepare them to be contributing adults in their communities. As schools and social institution consider how to 
integrate youth into process of community development, it is important to ensure that condition exist which will support the development of youth into healthy, contributing adults. These contextual arenas will allowed youth and adult to have partner in addressing many social problems, leading to greater understanding and share norms and values. Adult must recognize that adolescent life is also impacted by multiple systems and as adult. They need opportunity to lead and represent within their greater community setting toward progress and policy planning implementation and evaluation (Lane, 1992). The merging of youth development and community building has been at the core of recent youth engagement literature. Cohill (1997) has described that youth must be fully engage and involve in change effort, if they are to function as effective member of society. By recognizing that youth have the capacity to lead, adult can provide important support in shifting youth leadership development from a skill based orientation to an essential investment in the future (Lane, 1992).

It is the merging of youth development and community development that enables youth leadership to emerge. Adolescent should become actively involved in the design of community program and policies. Their level of cognitive, moral and social development enable them to rise to more complex challenge as the transmission to adulthood and the responsibility that come alone with it (Gambone, 2002). Such involvement also set the stage for long term involvement, leadership development effort. In order to develop youth leadership with organizational structure, setting specific necessary condition must be in place for youth leadership to work effectively. Mechanism for advancing youth into specific skills (such as reading budget and working on committee) and training adult to explore their pre-existing assumption and stereotypes about youth as community leaders (Sherrod 2000).

Youth leaders can also play important roles such as identified youth issues developing youth programmes, leading youth programmes delivering and representing youth in the community (Dyfoos, 1990). As a more meaningful involvement of youth, the organization and community changes that reflect the priority of youth will stimulated greater participation by youth in future decision making. Youth in the organization and community may all have potential benefit from a greater investment in them as becomes engage on leadership roles within their communities (Lane, 1992).

Another area where the youths play a role in the community development process is that of security. It is evident in many communities that no meaningful development can take place where the security of life and properties are not guaranteed. The youth play vital role in this regard; they are seen as the watch dog of the community. Youth comprise the core of vigilante group and other security outfit in their community and in safe guarding the life and properties of the member of their community. This is vividly seen in Borno and Yobe State currently where youths were able to restore peace in state capitals.

United Nation (2000), posit that, more can be done to this nurture, these productive behavior of the youth constitute crucial development asset when they positively empowered to be active participants. Therefore, including youth in development process is important as youth make up the majority of the local population in many community hence their activities are crucial for all community needs. And regardless of the current status of youth in their communities, they are the custodians of their communities.

Furthermore, through the National Youth Service Corps (NYSC) scheme among others Nigerians youth have been able to actively participate in the actualization of some of these laudable national objective as contain in the second and third national development plan of 1970, 1974,1975 and 1979 respectively, which has also enhance community development. For example, via the NYSC scheme, youth have enhance and substance the migration of labour from one part of the country to another. Within the framework of the scheme, youth are afforded the opportunity to explore the diverse culture of Nigerian communities and provide essential services in health, teaching vocation and community development where such service are in near absent or absence in entirely.

Also, in the traditional African society, the strategic placement of youth in the overall economic political and social transformation of the society and community is well organized. Youth formed the bulk of the agrarian labour force from which food security and availability is guaranteed in rural community. Youth also formed the center piece of nearly all voluntary association and active bodies whose objectives is to supplement and complement the effort of the elderly in the society and community at large. Youth are also the propelling force of support industry their participation in the industry has raised the status of many societies and communities in the world. Through sport unity is strengthened and social solidarity promoted as people come together to participate. The level of support and opportunity youth experience during adolescent has been link to the likelihood that they will achieved good outcome as young adults (Gambone, 2002). This is one of the primary way that youth setting such as the once study here contribute to the developmental trajectory youth follow their ultimate ability to thrive as self sufficient, healthy contributing member of communities. Youth has unique organizational context that facilitate relationship. The small size of youth organizing agencies, with small youth adult ratios, created increase opportunities for supportive relationship. 


\section{Theoretical Framework}

Various scholars have attempted to explain social phenomena, in different ways depending on the situation at hand. Science introduces theories in order to explain empirical generalization or law to answer key question in human interaction, they posited that the theory does not means ideal speculation or conjecture. In fact, for an explanation to be called a theory in science, it usually implies considerable supporting evidence. Durkheim (1902) view a theory as a set of hypothesis or speculation which forms a deductive system, that is which arranged in such a way that form some of the hypothesis as premises of other entire hypothesis logically follows. It summarized existing knowledge and provides explanation to observed event and relationship on the basic of the explanatory principles embodied in the theory. Generally, a theory is a set of proposition, ideas, assumption, and hypothesis.

Functionalism has a long history in human society, the proponent scholars in the development of the functionalist paradigm are the work of other sociologist like Auguste Comte (1788 - 1857), Herbert Spencer (1820 - 1903), Emile Dukhiem (1858 - 1917) and Talcott Parson (1902 - 1979), which tend to explain society as a holistic system because it is a system of integral part which connect system and subsystem to work together for the betterment of society and its members. To the view of the above scholars they sees society like living organism in which every part of the organism make an input to the survival of society. In this view, emphases the way in which each part of the society is structured to maintained the stability of it. They argued that the society as an entity share the same value, norms, social order according to these theorist arise in the society from internationalization of the norms embodied in the law. Society according to this model has normative codesignating and which in appropriate behavior individual are rewarded or punished as they conform or deviate from norms. These norms are blueprint within which goals are achieved in the society. Structural functionalism conceived society as a sustaining system which consist of interrelated and inter-dependent part such as family, economic, religion, education and legal system. These compel function to meet their needs and also that of the larger society. Thus, social unit are seen as not working in isolation from the whole system. In order to survived, these subsisting were established (Parson, 1964).

The part according to Parson (1964) is connected so closely that each one part if affected all of the part is affected as well as the system as full. Functionalist considers a function that contributed to the part of a larger system and its effect on other part of the system. Functionalist also sees society, like the human body as being made up of a part, like the various body part, each of the social part function to maintain a larger system. For example educational system on Nigeria, the function of education is to transmit knowledge to the younger generation. So if the primary school education is affected the full system of education will be affected.

Therefore, functionalist theory is trying to explain the role of youth in community development. They look at it from the formation of youth association. These association are form by the youth which seen as functional part of the community. The functionalist argues that these association or organization that is formed by youth helps them to developed ideas that will assist them in bringing development to their communities. The functionalist consider youth as a member of their communities who constitutes an integral part of its development action and effort of the youth turn to their community in better place. It is true that functionalist emphasis that youth participation in their communities contribute to the stability and grow of the community they also recognize that the system does not remain static, there is grow in one part of the society.

Functionalist considers the function that contributes to the part of a larger system and its effect on other part of the system. In Damaturu local government community development has stated to emerge as an instrument by which government could relate itself to youth in passive fashion and create channel of communication between the youth and government. It makes youth, elder and the government coming to a consensus on how to develop their communities. Both the communities and youth benefit greatly from the involvement of young resident in some aspect of community development in Damaturu, local government. Youth also organize themselves for identification of their needs with maximum reliance on their own initiative and resources, supplemented with assistance in any form from governmental and nongovernmental agencies.

\section{Methodology}

The research methodology has been designed to assess the youth participation in community development in Damaturu Local Government area in Yobe State.

\section{Target Population}

This is a target group which the researcher is interested in studying or observing in which he intends to obtain information and draw a conclusion. Damaturu local government the state capital of Yobe State has heterogamous population of 301,954 according to the 2006 population and housing census figure. A total number of male are 175,125 and female are 136,835.the target population covered all youth organization in Damaturu local government area and purposive random sampling techniques is adopted to select group of youth to get answers. 


\section{Sample Size and Sampling Techniques}

From the eleven wards (11) in Damaturu Local government Area six (6) wards were purposively selected. The researcher selected Maisandari/Waziri Ibrahim, Gwange, Damaturu central, Nayinawa, Bindigari/Fawari and Kukareta wards respectively. Twenty five respondents were selected from each ward, and used simple random sampling to obtain a total of one Hundred and fifty (150) respondents. Therefore only one hundred and fourty questionnaires were retrieved from the field.

\section{Method of Data Collection}

Survey method will be appropriate in this research endeavor in the collection of data. This as a result of the nature of this research and type of information needed. The researcher make used of two major instruments for data collection. These are primary and secondary sources of data collection.

The primary sources of data collection which will get from the questionnaire which comprising of carefully designed question for respondents to answer. Both the open ended and close ended question were designed in a way that the respondents response will be limited while the close ended was given provision for respondents to give their personal view about the questions. Questionnaire contained two sections the first section will focus on the bio - data of the individual respondent while the second section will deal with general view of the study.

The secondary sources of data were gotten from the already existing sources. These sources of data are mostly found in the journal, textbook, internet printout and other information storage.

\section{Method of Data Analysis}

The analysis is one of the most important stages in social research because it determines how the information on data gathered is analyzed and explained for proper analysis of the subject matter. Descriptive statistical tools such as frequency, and percentage, were used to analyze the facts sought by the questionnaire.

\section{Data Presentation and Intepretation}

Table 4.1 Respondents opinions on youth contributions to Community Development.

\begin{tabular}{|l|l|l|}
\hline RESPONSES & FREQUENCY & $\begin{array}{l}\text { PERCENTAGE } \\
(\%)\end{array}$ \\
\hline Through farming & 50 & 35.7 \\
\hline Through politics & 30 & 21.4 \\
\hline Through communal labour & 20 & 14.3 \\
\hline Formation of vigilant group for security and maintenance & 20 & 14.3 \\
\hline Others & 20 & 14.3 \\
\hline Total & 140 & 100 \\
\hline
\end{tabular}

Sources: Field survey 2014

The table indicated that, those that contribute through farming has the highest respondents than those contribute through politics which has an average respondents than those in communal labour, vigilant group and others. Sherrod (2002), said that, youth are the most vital resources for community development, the ability and capacity of the youth to derived it benefit from, and contribute to community development depends on whether they are correctly guided and adequately mobilized.

Table 4.2 Respondents income in the community

\begin{tabular}{|l|l|l|}
\hline RESPONSES & FREQUENCY & PERCENTAGE(\%) \\
\hline Government & 30 & 21.4 \\
\hline Nongovernmental organization & 50 & 35.7 \\
\hline Volunteer community service & 60 & 42.9 \\
\hline Total & 140 & 100 \\
\hline
\end{tabular}

Sources: Field survey 2014

The result in this table shows that, the volunteer community service has the highest respondents than nongovernmental organization which falls between the average respondents than government which has the lowest respondents. Lane (1992), asserted that youth in Nigeria can be put in Public or Private Ventures (PPV) which reflect the similar effort of the youth. It has also joint with community organization in several cities whether rural or urban communities to increase neighborhood support for youth development in the community.

Table 4.3 Respondents awareness on youth's empowerment programmes

\begin{tabular}{|l|l|l|}
\hline RESPONSES & FREQUENCY & PERCENTAGE (\%) \\
\hline Yes & 98 & 70 \\
\hline No & 42 & 30 \\
\hline Total & 140 & 100 \\
\hline
\end{tabular}


Sources: Field survey 2014

The study reveals that, majority of the respondents are answered yes they are aware of the programme, while few of the respondents answered no they are not aware of the programmes. Therefore, this question, the researcher match it with the idea of Gambone (2002), asserted that, it is the merging of youth development and community that enable youth leadership to emerge in programme. Adolescent should become actively involved in the design of community programmes and policies. Their level of cognitive moral and social development enables them to rise, to more complex challenge as the transmission of adulthood and responsibilities that come alone with it.

Table 4.4 Respondents attended community development programmes.

\begin{tabular}{|l|l|l|}
\hline RESPONSES & FREQUENCY & PERCENTAGE(\%) \\
\hline Yes & 98 & 70 \\
\hline No & 42 & 30 \\
\hline Total & 140 & 100 \\
\hline
\end{tabular}

Sources: Field survey 2014

In this table, the result indicated that, the majority of the respondents said yes they have attended the programme, while other said no, they have not attended any programme. Lane (1992) posited that, today national youth development organization and intermediaries as well as local based, youth development organization are engage in expanding their vision and practice to youth development. Community youth development now serve as a framework for guiding staff and organization development and programme design.

Table 4.5 Respondents types of programmes attended

\begin{tabular}{|l|l|l|}
\hline RESPONSES & FREQUENCY & PERCENTAGE(\%) \\
\hline Poverty alleviation & 55 & 39.3 \\
\hline Nongovernmental organization & 35 & 21.4 \\
\hline Annual cultural festivals & 30 & 25 \\
\hline Others & 20 & 14.3 \\
\hline Total & 140 & 100 \\
\hline
\end{tabular}

Sources: Field survey 2014

The table indicated that, majority of the respondents engage in poverty alleviation programme than nongovernmental organization whose falls between the average respondents while cultural festival and other has the lowest respondents. Ekong (2003), asserted that, community development in developing countries generally entail the emphasis of youth by the local community. He further stated that, involvement in programmes entails understanding the nature of the problem involved, those directly involved and those peripherally affected.

Table 4.6 effectiveness of establishes programmes by the Youth in community development.

\begin{tabular}{|l|l|l|}
\hline RESPONSES & FREQUENCY & PERCENTAGE(\%) \\
\hline Yes & 98 & 70 \\
\hline No & 42 & 30 \\
\hline Total & 140 & 100 \\
\hline
\end{tabular}

Sources: Field survey 2014

The study shows that, majority of the respondents answered YES the programmes is effective while few respondents answered NO the programmes is ineffective. Lane (1992), said that, community youth development now serve as a framework for guiding staff and design programmes. He further stated that the national network for youth describe it, as a holistic system and strength based approach to work with young people. It also assured the effectiveness of programmes by respecting one another, creating healthy youth, strong family and responsible communities.

Table 4.7 various problems faced by the Youth in community development.

\begin{tabular}{|l|l|l|}
\hline RESPONSES & FREQUENCY & PERCENTAGE(\%) \\
\hline Inadequate funding from the leaders in the community & 50 & 35.7 \\
\hline Lack of co-ordination from the youth & 35 & 25 \\
\hline Poor communication and knowledge about the community development & 30 & 21.4 \\
\hline All of the above & 25 & 17.9 \\
\hline Total & 140 & 100 \\
\hline
\end{tabular}

Sources: Field survey 2014 
The table shows that, inadequate finance funding from the leaders in the communities as a problems face by the youth in community has highest respondents than lack of co-ordination from the youth which have average respondents and those falls between poor communication and all of the above. Rodney (2005), asserted that, despite the youth in community development are facing problems and this problems do not begin in isolation and therefore, cannot be solved in isolation. He went further to say that the mission is to create an effective continuity for care design to help children, youth and families achieve their potential needs.

Table 4.8 Respondents suggestion to solve the problems

\begin{tabular}{|l|l|l|}
\hline RESPONSES & FREQUENCY & PERCENTAGE(\%) \\
\hline $\begin{array}{l}\text { Re-orientation and financial moral support about all the } \\
\text { stakeholders in community }\end{array}$ & 359.3 \\
\hline Training the youth in entrepreneurship & 50 & 35.7 \\
\hline Improve moral value in the community & 20 & 17.9 \\
\hline None of the above & 10 & 7.1 \\
\hline Total & 140 & 100 \\
\hline
\end{tabular}

Sources: Field survey 2014

The table indicated that, re-orientation, financial and moral support about the stakeholder has the majority of respondents than training the youth in entrepreneurship while improve moral value in the community has lowest responses than none of the above to address problems faced by the youth in community. Sherrod (2002), posit that, civic engagement of the youth in community development such as civic education and an opportunity for involvement in school curriculum activities are an important element of community involve for youth to address some various problems faced by the youth. Lane (1992), posit that, in this contextual arena, we would allowed the youth and adult to have partner in addressing many social problems leading greater understanding and share norms and values in solving problems in community.

Table 4. 9 Youth performance during programme exercise

\begin{tabular}{|l|l|l|}
\hline RESPONSES & FREQUENCY & PERCENTAGE $(\%)$ \\
\hline Yes & 98 & 70 \\
\hline No & 42 & 30 \\
\hline Total & 140 & 100 \\
\hline
\end{tabular}

Sources: Field survey 2014

The study shows that, the majority of the responses answered YES youth are performing their duties during programme exercise while others answered NO youth are not performing their duties during programmes exercise.

Table 4.10 Changes Youth brought from community development programme

\begin{tabular}{|l|l|l|}
\hline RESPONSES & FREQUENCY & PERCENTAGE(\%) \\
\hline Positive changes & 70 & 50 \\
\hline Negative changes & 45 & 32.1 \\
\hline None of the above & 25 & 17.9 \\
\hline Total & 140 & 100 \\
\hline
\end{tabular}

Sources: Field survey 2014

The research shows that, the majority of the responses are of the view that youth brought positive changes in the community, than that response that youth brought negative changes to the community while others are of the view that none of the above brought changes in the community. United Nation (2002), posited that, more can be done to these nature, this productive behavior of the youth as they constitute crucial development when they positively empowered to be active participant. therefore, including youth in development is important as youth make up the majority of the local population in many communities, hence their activities are crucial to all community need. They further stated that, youth are the custodian of the community.

\section{Discussion of Finding}

This research work revealed that the youth contribute to the development of community through farming, politics, communal labour, formation of vigilant group for securities and maintenance of life and properties. It is also clear from the finding that most of the youth in the study area were participating in community development through farming and other self initiated work in order to enhance their living standard.

The research further revealed that orientation financial and moral support about the stakeholders in the community or training the youth in entrepreneurship can address the problems faced by the youth in this community. The study also shows that skill acquisition and job creation could develop youth economic potential 
and self reliance. It is also the reactivation of agricultural economics can create employment opportunities for youth and make them self reliance.

Moreover, inculcation of religious beliefs and moral instruction to youth can make them behave decently and also think on how to develop their community. Consequently, the finding also reveals that careful attitude by the government is one of the factors that contribute to the problems faced by the youth in community development. The study further revealed that through the formation of association by the youth can help or support the government, and create awareness on government policies and programmes.

\section{Conclusion}

Youth involvement in community development should be central to the development effort of any community. From this perspective, community development is facilitated by the ability of the local needs. Their need for extension workers, programme developers and policy planners to better understanding the role of youth are energetic and custodian of societal norms and values.

Whatever social plan that the youth are involved, such will continue even after the adult may have pass on. The only different may be that such plan or attend some levels of modification. Therefore, they are in position to be suitable and long term contributors that help to guide this process. They presented vast and untapped resources for immediate and long term community development. It is important to note that, we pay a price when we derived children of the exposure to the values, principle and education they need to make them good citizen. Therefore whatever positive effort that is going on in our communities without youth involvement is a waste project. This is because when the old past on what become on such effort, or better still when the youth are not well inculcated in the value and principles of the society, they tend to build their own value and principle which may result in to a lot of social vices and all the development effort will be thwarted.

\section{Recommendation}

Based on the finding of this research, the following recommendations were suggested to enhance and increase the level of involvement of youth in community development.

- The government should provide youth a conducive-atmosphere to become long term contributor to community organization. This reflect the significant of local network and may require active collaboration with youth than before in order to engage them in way that can open opportunities for them to contribute.

- Awareness or enlighten is very crucial and the youth should be given adequate source of information to make them have a firsthand knowledge about what is happening in their communities. It is also very important for public enlighten programmes to be organize from time to time to educate both the youth, their parent and other members of the community on the significant of youth participation in community development project.

- Adequate assistance and encouragement should be given to the youth by the elite in these communities by setting up cottage industries where the youth can channel their energies and enhance their participation in community development.

- It is important to note that, the elite or leaders, government and nongovernmental organization to understand that most of the social problems that they spend huge amount of money to tackle, can only be solve by involving the youth, so that the youth can faced this problems. This will allowed the youth to see themselves in the environment when the youth are transforming from passive citizen waiting for adulthood to active citizen engaging in social change. This is automatically reduced a lot of social problems since the youth whom it neglected become ready tools for some mischievous adult to cause chaos are no were to be found in any negative activities but will make well oriented responsible contribution to the society.

\section{References}

[1]. Adedoyin S. F. (1997) Essential of General Studies, Culture, Computer, Agriculture, the Role on the Nature and Scope of Rural Development. CESAP, Olabisi, Onabanjo

[2]. Chambers (1978) “Project Selection for Poverty Focused Rural Development: simple is Optional” World Development, 6 Edition.

[3]. Cohill M. (1997), Youth Development and Community Development: Premises and Challenges of Convergence Community and Youth Development Series, Volume 2 International Youth Formation.

[4]. Connell J. (1992), The Importance of Learning about and Building on the Policies Programs and effects of Voluntary Serving Organization. Philadelphia: Public/Private Ventures.

[5]. Connell j. P, (2000), Youth Development in Community Setting. Issues, Challenge and Direction (281-300). Philadelphia Public/Private Ventures.

[6]. Dryfoos J. (1990), Adolescent at Risk Prevelence and Prevention. New York: Oxford press.

[7]. Ekong E. E. (2003) an Introduction to Rural Sociology. Dove Educational Publisher, 80 Wellington Barry way Uyo pp. 323 324. 
[8]. Gambone J. F. (2002), Testing key Link in a Community Action Framework for Youth development. Philadelphia. Youth Development Strategic, Inc and Institute for Research and Reform in Education.

[9]. Ginwight S. and James J. (2002), Social Justice, Organizing and Youth Development, New Direction in Youth Development.

[10]. Jibowo A. A. (1992) Essential of Rural Sociology. Gbeni Sodipo Press, Abeokuta p. 229

[11]. Lane R. (1992), “on the Journey to Community Youth Development” New Design for Youth Development (14 - 18).

[12]. Rodney, W (2005), How Europe Underdeveloped Africa. Introduction by Vincent

[13]. Harding,2009 Edition. Panaf, publishing, Abuja, Lagos pretoria

[14]. Sherrod L. (2000), The Development of Citizenship in Today's Youth. Journal of Applied Development Science.

[15]. United Nation (2002): http/www.fril. org. United Nation Economics and Social Commission for Asia and the Pacific. Youth Participation Manual.

[16]. Wynn J. (1987), Communities and Adolescent an Exploration of Reciprocal Support: Chicago Chapin Hall Centre for Children, the University of Chicago. 